\title{
Primary angioplasty in a community hospital in the USA
}

\author{
Insights into the advantages and limitations
}

Primary angioplasty as a reperfusion strategy for the treatment of acute myocardial infarction has been controversial. Despite the controversy, this reperfusion strategy has been used increasingly since its introduction in 1983, and now about $8 \%$ of patients undergoing reperfusion therapy in the United States receive direct angioplasty. ${ }^{1}$ In the Moses $\mathrm{H}$ Cone Memorial Hospital primary angioplasty has been the primary reperfusion strategy for acute myocardial infarction since 1984 . This 548 bed acute care hospital serves as a community hospital for the city of Greensboro, North Carolina with a population of 190 000, and also serves as a regional referral centre for several smaller neighbouring hospitals within a 40 mile radius. Our facility has three busy catheterisation laboratories with a staff of 21 technicians, three of whom are on call each night. We now perform approximately 3400 diagnostic catheterisation procedures and 1300 interventional procedures a year. From 1984 through 1993 we treated over 900 patients with acute myocardial infarction with direct angioplasty and our patient characteristics and outcomes are summarised in tables 1 and 2. Our experience over the past 10 years has given us some insights and perspective into some of the advantages and limitations of this approach.

OUTCOMES WITH PRIMARY ANGIOPLASTY

Primary angioplasty clearly provides the highest coronary patency rates of any reperfusion strategy. The Primary Angioplasty Registry, in which we participated, documented patency (TIMI flow grades 2 or 3 ) in $99 \%$ of patients undergoing direct angioplasty, and $97 \%$ of these patients achieved normal or TIMI 3 flow (fig 1). ${ }^{2}$ The

Table 1 Baseline characteristics of 907 patients treated with direct coronary angioplasty (1984-1993)

\begin{tabular}{lcl}
\hline Characteristic & $\begin{array}{l}\text { Thrombolysis } \\
\text { candidates } \\
(n=775)(\%)\end{array}$ & $\begin{array}{l}\text { Not thrombolysis } \\
\text { candidates } \\
(n=132)(\%)\end{array}$ \\
\hline Age (yr, mean (SD)) & $59(11)$ & $63(12)$ \\
Gender (female) & $203(26)$ & $45(34)$ \\
Prior myocardial infarction & $161(21)$ & $38(29)$ \\
Prior bypass surgery & $28(3 \cdot 6)$ & $10(7 \cdot 6)$ \\
Anterior infarction & $312(40)$ & $64(48)$ \\
Multivessel coronary disease & $422(54)$ & $91(69)$ \\
Acute ejection fraction (\%) (mean (SD)) & $53(13)$ & $44(14)$ \\
Reperfusion time (h) (mean (SD)) & $3.9(2 \cdot 0)$ & $8.9(7 \cdot 1)$ \\
\hline
\end{tabular}

${ }^{\star}$ Killip class III or IV or reperfusion time $>12 \mathrm{~h}$.

Table 2 Hospital outcomes of 907 patients treated with direct coronary angioplasty (1984-1993)

\begin{tabular}{lcc}
\hline Outcome & $\begin{array}{l}\text { Thrombolysis } \\
\text { candidates } \\
(n=775)(\%)\end{array}$ & $\begin{array}{l}\text { Not thrombolysis } \\
\text { candidates }^{*} \\
(n=132)(\%)\end{array}$ \\
\hline Successful PTCA & $731(94)$ & $121(92)$ \\
Mortality (30 day) & $43(5 \cdot 5)$ & $35(27)$ \\
Non-fatal reinfarction & $35(4 \cdot 5)$ & $8(6 \cdot 1)$ \\
$\begin{array}{l}\text { Recurrent ischaemia } \\
\text { requiring intervention }\end{array}$ & $23(3 \cdot 0)$ & $3(2 \cdot 3)$ \\
Stroke & $7(0 \cdot 9)$ & $3(2 \cdot 3)$ \\
\hline
\end{tabular}

^Killip class III or IV or reperfusion time $>12 \mathrm{~h}$.

†Two strokes were haemorrhagic in the not thrombolysis group

PTCA, percutaneous transluminal coronary angioplasty.

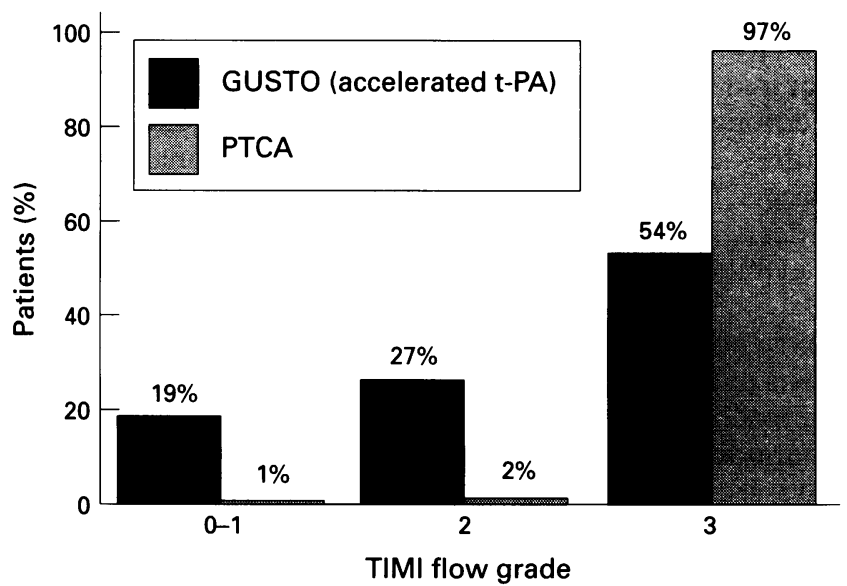

Figure 1 TIMI flow in the infarct-related artery after accelerated $t-P A$ in the GUSTO trial $^{3}$ versus primary angioplasty (PTCA) from the Primary Angioplasty Registry. ${ }^{2}$

highest patency rates at 90 minutes reported in the GUSTO trial were $81 \%$ with accelerated t-PA (tissue plasminogen activator, alteplase) and only $54 \%$ of these patients achieved TIMI 3 flow (fig 1). ${ }^{3}$ In the GUSTO trial, hospital mortality was substantially lower in patients with TIMI 3 flow than in patients with TIMI 0 or 1 flow $(4.3 \% v 9 \%)$, and mortality in patients with TIMI 2 flow was similar to that of patients with TIMI 0 and 1 flow (7.9\%). This suggests that only TIMI 3 flow should be considered "true patency," and that the higher patency rates and better flow achieved with direct angioplasty are likely to translate into improved outcomes. Indeed, data from the recent randomised trials have shown that primary angioplasty has a clear advantage over thrombolytic strategies in the prevention of reinfarction and recurrent ischaemia. ${ }^{45}$ Although there have been no large randomised trials designed to assess mortality differences between primary angioplasty and thrombolytic therapy, data from non-randomised trials and data from small randomised trials suggest that primary angioplasty may have mortality benefit in high risk patients such as patients with cardiogenic shock, anterior infarction, and those who are elderly. ${ }^{4-6}$ Also, the risk of intracerebral haemorrhage, while not absent, is substantially lower with primary angioplasty than with thrombolytic therapy. ${ }^{245}$

\section{AVAILABILITY OF PRIMARY ANGIOPLASTY}

Despite several clear advantages, primary angioplasty is used to treat few patients with acute myocardial infarction because its availability is limited and there are logistical problems associated with its delivery. Direct angioplasty requires a well-equipped interventional laboratory, experienced operators, and catheterisation laboratory personnel who are able to respond quickly 24 hours a day. Currently only $18 \%$ of hospitals in the United States are equipped to perform angioplasty, and not all of these can do this on an emergency basis. ${ }^{7}$ Performing angioplasty on an emergency basis requires a willingness and commitment on the part of physicians and catheterisation 
laboratory personnel to interrupt busy schedules during the day and to mobilise personnel at night. In our hospital this has become an accepted part of the day-to-day practice, but not all laboratories are willing to accept this commitment.

The need for on-site surgical backup when direct angioplasty is performed has been controversial. In the Primary Angioplasty Registry only $1 \%$ of patients required emergency surgery for failed angioplasty, but an additional $4 \%$ of patients underwent emergency bypass surgery as primary therapy instead of coronary angioplasty. ${ }^{2}$ These data indicate that on-site surgical support is desirable, and this places further limitations on the availability of direct angioplasty.

\section{COST COMPARISONS}

Costs have also been a concern with the direct angioplasty approach. However, in institutions where catheterisation laboratories are available, studies have shown that hospital stays are shorter and costs comparable or lower when a direct angioplasty rather than a thrombolytic strategy is used. ${ }^{8}$ The shorter stay is partly attributable to fewer recurrent ischaemic events but may also be because knowledge of the coronary anatomy and left ventricular function is acquired on admission. This permits risk stratification and allows for early discharge of low risk patients and early triage of high risk patients to further revascularisation. The data suggest that the initial expense of immediate angioplasty is offset by a shorter hospital stay, fewer recurrent ischaemic events, and fewer readmissions, resulting in overall costs that are comparable or lower. In settings where catheterisation laboratory facilities and personnel are currently available, primary angioplasty is often an economical approach to coronary reperfusion. However, it does not appear that the benefits of direct angioplasty are enough to justify the expense of expanding catheterisation laboratory facilities to make it available to everyone.

\section{ELIGIBILITY FOR REPERFUSION THERAPY}

Probably the biggest potential advantage of direct angioplasty is that it offers reperfusion therapy to many patients who are not eligible for thrombolytic therapy because of the risk of bleeding. In the GUSTO trial only $33 \%$ of patients with acute myocardial infarction received thrombolytic therapy (fig 2). ${ }^{9}$ In our institution, which uses direct angioplasty as a primary reperfusion strategy, $48 \%$ of patients with acute infarction received reperfusion

\section{GUSTO registry ( $n=3376) \quad$ PTCA registry $(n=449)$}

\section{Treated: Thrombolysis Treated: Thrombolysis $6 \%(n=28)$ ( $n=1099$ )}

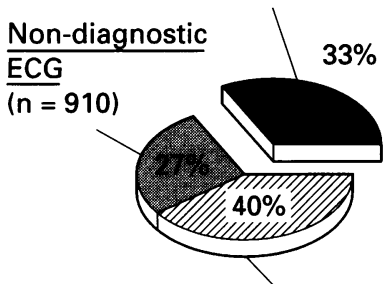

Not treated $(\mathrm{n}=1367)$

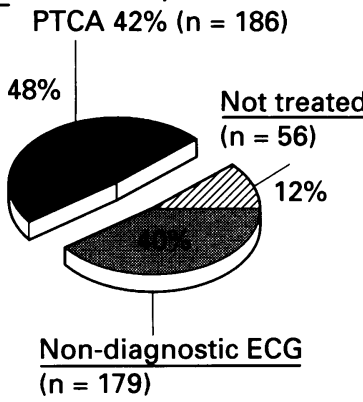

Figure 2 Proportion of patients treated with two reperfusion strategies. Data on the left are from the GUSTO registry. ${ }^{9}$ Data on the right are from our institution, which uses direct angioplasty as a primary reperfusion strategy. ${ }^{10}$ therapy (42\% with direct angioplasty and $6 \%$ with thrombolytic therapy) (fig 2). ${ }^{10}$ Almost all patients who were not treated with reperfusion therapy at our institution were not eligible because of a non-diagnostic electrocardiogram (no ST segment elevation), late presentation, or co-morbid disease.

\section{SELECTION OF PATIENTS FOR PRIMARY ANGIOPLASTY}

In institutions where catheterisation laboratory facilities and personnel are available, the clinician is faced with the question of which patients with acute myocardial infarction should be treated with primary angioplasty. Clearly, patients with contraindications to thrombolytic therapy because of the risk of bleeding who would otherwise not receive reperfusion therapy are often excellent candidates for treatment with primary angioplasty. Direct angioplasty with adjunctive treatment (such as intra-aortic balloon pumping) seems to have an advantage over thrombolytic therapy in the treatment of patients with cardiogenic shock and pulmonary oedema. ${ }^{6}$ Other high risk patients, including patients with anterior infarction and elderly patients, may derive more benefit from primary angioplasty than from thrombolytic therapy. ${ }^{4}$ Patients with prior bypass surgery have low rates of reperfusion with thrombolytic therapy and probably can benefit more from primary angioplasty. ${ }^{11}$ Conversely, most low risk patients who have generally been enrolled in thrombolytic trials are likely to do well with either primary angioplasty or thrombolytic therapy.

In our view, direct angioplasty and thrombolytic therapy are complementary. Direct angioplasty, when available, offers reperfusion therapy to many patients who are not eligible for thrombolytic therapy, whereas thrombolytic therapy is available at nearly all hospitals and offers proven mortality benefits to thrombolytic candidates. Both strategies are still evolving and, with improved equipment and technique for angioplasty, improved dosing regimens for thrombolytic therapy, and improved adjunctive therapy such as antithrombin and antiplatelet agents for both therapies, outcomes can be expected to continue to improve.

BRUCE R BRODIE Moses H Cone Memorial Hospital, Greensboro, North Carolina, USA

1 National Registry of Myocardial Infarction. Genentech: 1994, Genentech. 2 O'Neill WW, Brodie BR, Ivanhoe R, Knopf W, Taylor G, O'Keefe J, et al. Primary coronary angioplasty for acute myocardial infarction (The Primary coronary angioplasty for acute myocardial infarction

3 The GUSTO Angiographic Investigators. The effects of tissue plasminogen activator, streptokinase, or both on coronary artery patency, ventric-
ular function, and survival after acute myocardial infarction. $N$ Engl $\mathcal{F}$ ular function, and surviva

4 Grines CL, Browne KF, Marco J, Rothbaum D, Stone GW, O'Keefe J, et al for the PAMI Study Group. A comparison of immediate angioplasty with thrombolytic therapy for acute myocardial infarction. $N$ Engl f Med 1993;328:673-9.

5 Zijlstra F, Jan de Boer M, Hoorntje JCA, Reiffers S, Reiber JHC, Suryapranata $H$. A comparison of immediate coronary angioplasty with intravenous streptokinase in acute myocardial infarction. $N$ Engl $\mathcal{F}$ Med 1983;328:680-4

6 Bates ER, Topol EJ. Limitations of thrombolytic therapy for acute myocardial infarction complicated by congestive heart failure and cardiogenic shock. F Am Coll Cardiol 1991;18:1077-84.

7 Facilities and services in the United States. In hospital statistics 1992-1993. Chicago: American Hospital Association, 1992:208-9.

8 Gibbons RJ, Holmes DR, Reeder GS, Bailey KR, Hopfenspirger MR, Gersh BJ. Immediate angioplasty compared with the administration of a Gersh b. Itic a diate angioplasty compared with the administration of a infarction. $N$ Engl F Med 1993;328:685-91.

9 Ball S, Corrao J, Gore J, Goldberg R for the GUSTO Registry Investigators. Patients ineligible for thrombolytic therapy: The GUSTO Investigators. Patients ineligible for thrombolytic therapy: The GUSTO
acute myocardial infarction census log [abstr]. Circulation 1993;88:I-60.

10 Brodie BR, Stuckey TD. Primary angioplasty for acute myocardial infarcrodie BR, Stuckey TD. Primary angioplasty for acute myocardial infarc-
tion. In: Topol EJ, ed. Textbook of interventional cardiology (Update
11). Philadelphia: WB Saunders, 1993;158-72.

11 Kahn JK, Rutherford BD, McConahay DR, Johnson W, Giorgi LV, Ligon $\mathrm{R}$, Hartzler GO. Usefulness of angioplasty during acute myocardial infarction in patients with prior coronary artery bypass grafting. $A m \mathfrak{F}$ infarction in patients with
Cardiol 1990;65:698-702. 